\title{
LEPTOTHRIX ON THE CONJUNCTIVA AND IN THE MEIBOMIAN GLANDS
}

\author{
S. R. GIFFORD \\ From the Department of Bacteriology and Pathology, University of Nebraska, Omaha
}

Case 1 concerns a girl of 22 , who had been suffering with recurring attacks of conjunctivitis in both eyes for over a year. She showed, when first seen, a fairly severe conjunctivitis of the right eye, with some sticky secretion, thickening of the lower fold and marked congestion of the bulbar conjunctiva, and of the lid borders, extending along the meibomian glands. The right eye showed blepharitis with congestion of the lid borders and lower fold. The marked involvement of the bulbar conjunctiva and the inflammation along the meibomian glands made this appear somewhat different from the usual case of chronic conjunctivitis. A small amount of secretion was squeezed out of these glands in both eyes and smears and cultures made of it and of the secretion in the lower fold. A zinc collyrium and yellow oxid of mercury ointment were prescribed, and the patient was allowed to return to her home. Five weeks later she wrote that both eyes were improved and that there was no more discharge.

Smears of the secretion in the right lower fold showed numerous grampositive thread-like bacilli, many $10-15$ mikrons long by 1-1/1/1 thick. Some were curved, and many presented clear refractile subterminal bodies which appeared to be spores (fig. 1). The organisms were all extracellular. Smears from the meibomian secretion showed no organisms.

Inoculation on blood serum from the secretion in the right lower fold gave in 24 hours a pure culture of a gram-positive organism, appearing as long, unbranched, curved threarls, with some shorter rods. All forms were nonmotile. In cultures a few days old, coils of the threadlike organism were found 50-100 mikrons long. Spores were formed after 48 hours, seen subterminally on the rods and all along the threads, and taking Moeller's spore-stain. Some free spores were seen. No branching was observed. The serum was liquefied after 7-10 days.

Agar: Growth was best at $37 \mathrm{C}$., slight at room temperature. At $37 \mathrm{C}$. a spreading, grayish-white growth appeared in 24 hours, with a slightly feathery edge. No pigment was formed. The growth became slightly striated and roughened, but never showed the folded pellicle of the subtilis group. Cultures were made from single colonies on a plate and showed both short rods and thread forms (Figs. 2, 3 and 4).

Broth: A characteristic growth appeared. The broth remained clear, with no pellicle, while a feathery clump of growth accimulated slowly in the bottom, sending upward long threads that almost reached the surface after 10 days or more.

The milk was decolorized without acid-formation in 48 hours. Later there was peptonization; there was no coagulation.

Potato gave slow, invisible, slightly moist growth.

Gelatin was liquefied slowly around the upper part of the stab, at room temperature.

No odor developed. No gas was formed in sugar broth. The iodin reaction was negative in organisms from all mediums. Spores were most numerous on solid mediums, while the longest threads were found in liquid mediums. There was no growth anaerobically. 
Cultures left in the boiling water bath for one hour were capable of growth. Cultures left at room-temperature were viable after several months.

Animal Experiments.-Five minims of washings from an agar slant were injected intraperitoneally in a guinea-pig, which was found dead next morning. Smears from the exudate in the peritoneal cavity and from the omentum showed curved gram-positive organisms, 7-15 mikrons long, nearly all extracellular.

Three cultures from the peritoneal cavity showed the thread-forming organism in pure culture. The heart blood was sterile.

A second guinea-pig was injected subconjunctivally with 2 minims of the same suspension; it died in 2.3 hours; there was no reaction in the orbital tissues, but subscapular hemorrhages in the kidneys and enlarged spleen. Smears of the orbital tissues showed the characteristic organisms and cultures of the conjunctival sac, orbital tissues and heart blood showed the threadforming organism. The culture of the orhital tissues contained also a staphylococcus, but the others showed the organism in pure culture.

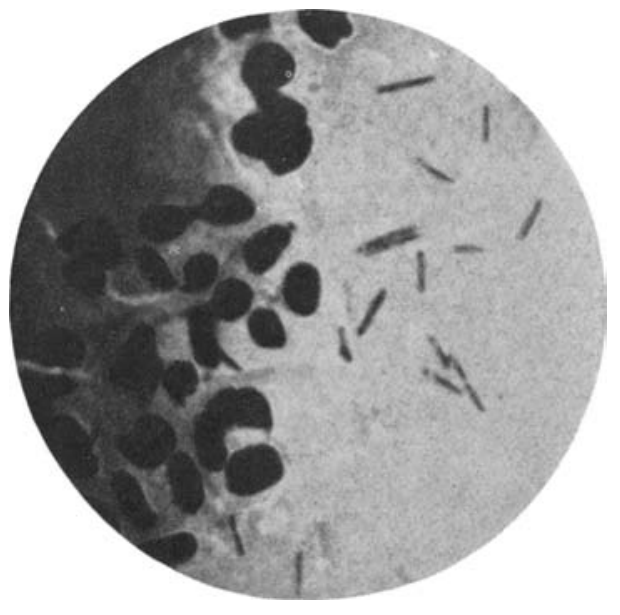

Fig. 1 (Case 1).-Smear of conjunctival sac; $\times 1200$.

Two drops of peritoneal fluid from the first guinca-pig were placed in the conjunctival sac of another pig, and the conjunctiva deeply scarified. It died the following night, and culture from the conjunctival sac showed some growth of the thread former, but this was overgrown by staphylococci. Only a small amount of heart blood was obtained and the culture was negative. Culture of the peritoneal sac gave staphylococci only.

Three other guinea-pigs died 5 to 10 days after one or more smaller injections of cultures, but the organisms were not isolated.

Two intraperitoneal injections in white mice were without effect.

Of two inoculations with loopfuls of growth in my own conjunctival sac, one produced only lacrimation and irritation lasting 24 hours, perhaps from the foreign matcrial; the other was without effect.

Small injections subcutaneously in rabbits were without effect, and two rabbits were subsequently immunized with increasing intravenous doses, without mishap. 
Ten day broth cultures were filtered through a No. 10 Chamberlain filter, but the filtrate was without effect on guinea-pigs in doses of $1 \mathrm{cc}$ given intraperitoneally.

Of two serums produced in rabbits, one agglutinated the homologous organism strongly at $1: 160$, less strongly at $1: 320$. The other agglutinated it strongly at $1: 320$, less strongly at $1: 640$. The organism was not agglutinated in any of the controls of normal salt, normal rabbit serum, or normal human serum. Neither serum agglutinated the somewhat similar organism from case 2 nor a similar thread-forming organism obtained as a contaminant on old serum. A strain of $B$. subtilis was tested with serum 1 , with negative results in all dilutions.

Case 2 concerns a man of 27 , who had symptoms suggesting eye strain for the past year. He was found to have a slight refractive error, but the congestion of the conjunctiva, especially on the tarsi in the region of the meibomian glands combined with a small amount of sticky secretion in the sac, seemed to

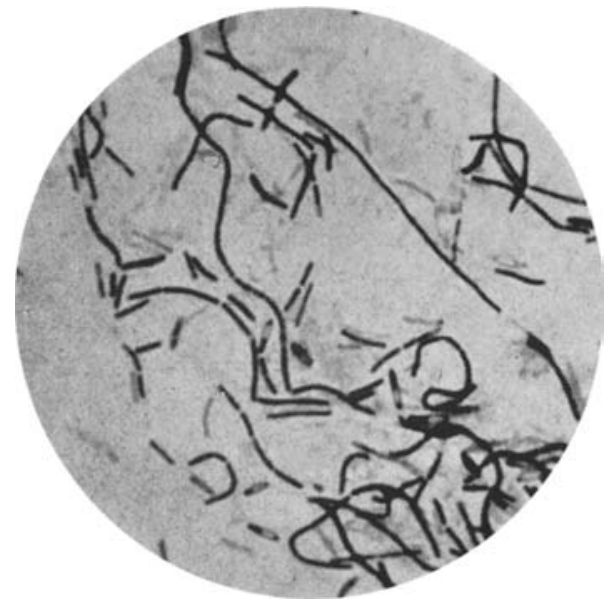

Fig. 2 (Case 1).-Smear of agar culture, $\times 1200$.

indicate another factor to account for it. No organisms were found in a smear of the conjunctival secretion. Pressure on the meibomian glands expressed an excess of whitish waxy, semifluid material from all their orifices.

A zinc collyrium was prescribed. The symptoms were relieved for a time, but in two weeks the patient returned with the same trouble. A correction for reading was given, and the glands thoroughly squeezed out again. This was repeated in 6 weeks; there was still an excess of fluid, though the symptoms were slight and the congestion much less.

Smears of the meibomian secretion showed a fair number of large bacilli with rounded ends. There were no true threads, but some of the bacilli were as long as a hay-bacillus, and all were much thicker than B. xerosis. Their reaction to Gram's stain varied, both gram-negative and gram-positive organisms of the same morphology being seen. Staphylococci were also found.

A broth culture showed a predominance of long gram-positive bacilli, some 10-12 mikrons in length, and often curved. Staphylococci and xerosis bacilli 
were also present. A pure culture of the long gram-positive organism was obtained from a plate, and after 2 to 4 days' growths many threads $10-20$ mikrons long were found and some 20-50 mikrons long. Some of these became clubbed at the ends, and subterminal spores were formed, which stained by Moeller's spore-stain. No branching was observed. The organism was nonmotile (Fig. 5).

Growth on agar at $37 \mathrm{C}$, appeared as a delicate grayish film, spreading over the medium, but not showing the wrinkling and filaments of the subtilis group.

Milk was slightly acidified but not coagulated. No pellicle was formed in broth. Blood serum was not liquefied. There was no growth at room temperature. The longest threads were formed in fluid medium.

A culture left in the boiling water broth for 12 minutes was capable of subculture. After 24 minutes it was no longer viable.

The growths from a 6-day agar slant injected intraperitoneally into a guinea-pig produced no effects. Scarifying the conjunctiva and rubbing in a

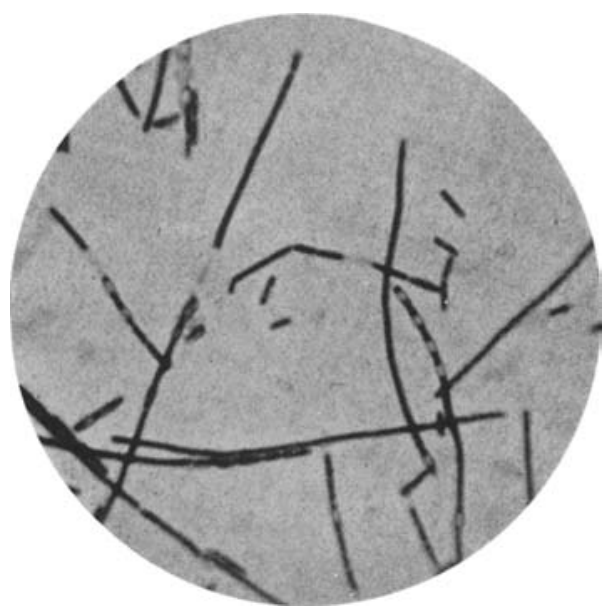

Fig. 3 (Case 1),... Smear of agar culture, showing spores in thrtads, $\times 1200$.

loop of growth produced no effects. Injection into the vitreous of a guinea-pig was negative.

Agglutination with serum I prepared against the organism from case 1 was negative. Whether the large bacillus in the smears was the same organism isolated in culture is questionable. The thread-formation in culture, however, was only marked after 2-4 days, so it is possible that the organism might not form threads on its human host and still form them in medium that favored complete development. The organism in the cultures, by its unbranched thread-formation, is seen to be a Leptothrix, and whether a pathogenic agent or not in this case, at least an inhahitant of the meibomian glands or lid-horder.

Case 3 concerns a man of 60 , who complained of a burning sensation and tited feeling in his eyes for over a year. Vision was brought up to $20 / 20$, both eyes, with suitable correction. Both eyes were inflamed, with lids thickened and reddened at the ciliary margin. On squeezing the lids, a large amount of semitransparent honey-like fluid was expressed from most of the meibomian 
glands. Smears and a culture were made of this. As the patient was obliged to return home at once, the lids were squeezed out as completely as possible, zinc chlorid 1 grain to the ounce was prescribed with zinc cerate ointment for the lids, and his physician was instructed how to express the fluid from the lids twice a week. A letter two months later reported no further symptoms while the treatment was continued.

The smears showed few organisms. After a long search, an area was found showing a fair number of curved, gram-positive threads, some 20-25 mikrons

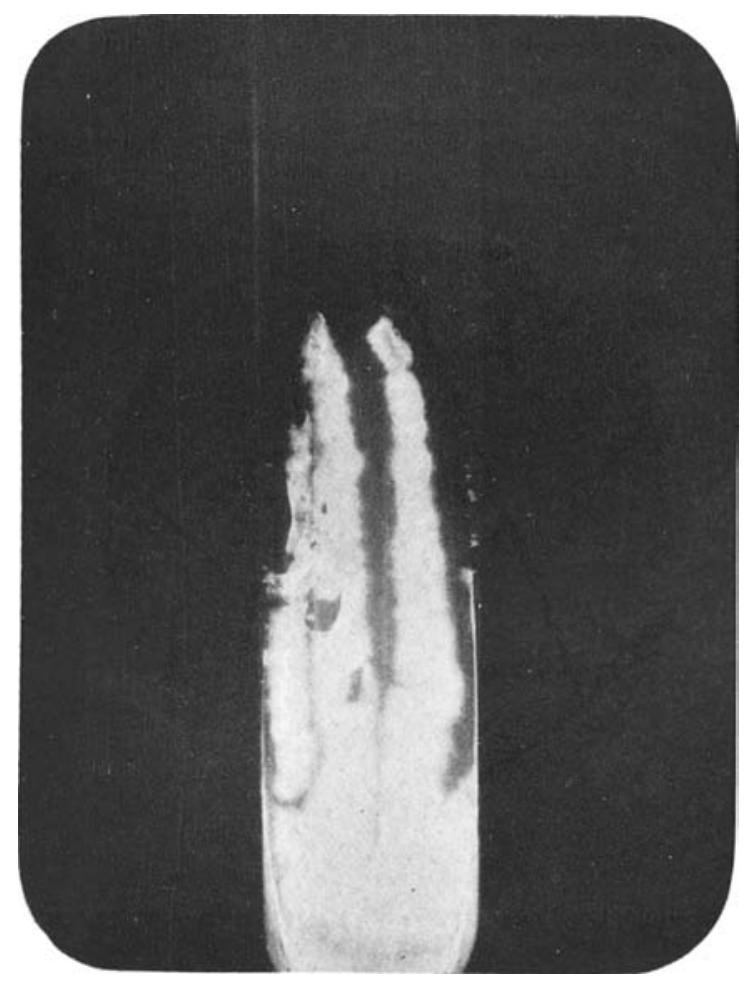

Fig. 4 (Case 1).-Four-day agar culture.

long, with shorter, gram-positive rods, some of which were curved (figs. 6 and 7). No branching was seen. A few gram-positive threads were found in other smears, also a few gram-positive diplococci. It seemed as if a small lump or concretion of the thread-like organisms had been broken up on the smear, while no such concretions had been obtained on the others.

An aerobic culture on blood serum was the only one taken and this showed staphylococci and xerosis bacilli. From the smears alone, a positive diagnosis between Leptothrix and Streptothrix can hardly be made, since it is known that Streptothrix may show branching only in culture. The threads were $1-1^{1 / 4}$ mikrons wide, however, about twice as wide as the threads of most strepto- 
thrices, and showed refractile sporelike bodies similar to those seen in the smears of case 1, so that the diagnosis of Leptothrix may be considered the most probable.

Smears from the secretion in two other cases of chronic meibomitis in which repeated examinations were made have shown a few large gram-positive bacilli, up to 12 mikrons long and sometimes curved. These were always associated

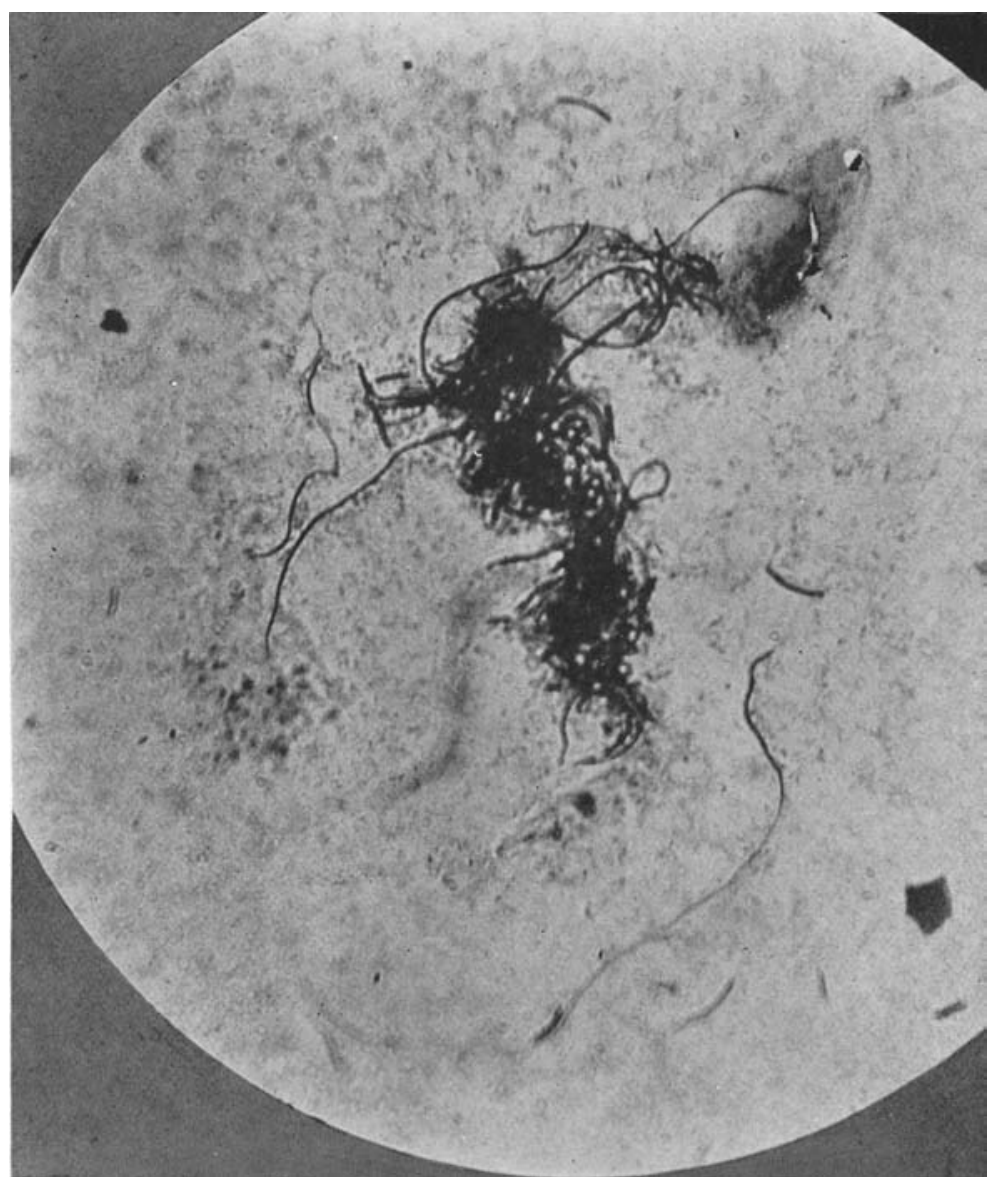

Fig. 5 (Case 2).-Smear of 48-hour culture.

with staphylococci and xerosis bacilli in the smears, and no pure cultures of organisms resembling the large bacilli have been obtained; therefore their identity is questionable.

Since the early description of Leptothrix by Robin in $1847^{4}$ there has been some confusion as to the classification of this organism, owing chiefly to the

1 Quoted in Klelss: Pulenherg's Fncyclopedia, 8, p. 260. 
fact that it has been so rarely grown in pure calture. Probably the most satisfactory classification of the higher bacteria is that of Petruschky," who divides the Hypomycetes into true molds and Trichomycetes; the latter is made to include, as four distinct groups, Leptothrix, Cladothrix, Streptothrix, and Actinomyces. The Leptothrix group is characterized by its formation of unbranched threads. The iodin-reaction, as a mode of distinction between Leptothrix and Streptothrix, may be considered as of no value, since Fricker ${ }^{\text {? }}$ and others have shown that it is due to the presence or absence of starch granules, which depends entirely on the previous nutriment of the organism.

The occurrence of Leptothrix in the body as a saprophyte has been well known since Bizzozero ${ }^{*}$ described Leptothrix epidermidis as a constant finding on the skin and Miller ${ }^{5}$ described four types of Leptothrix buccalis in the normal mouth.

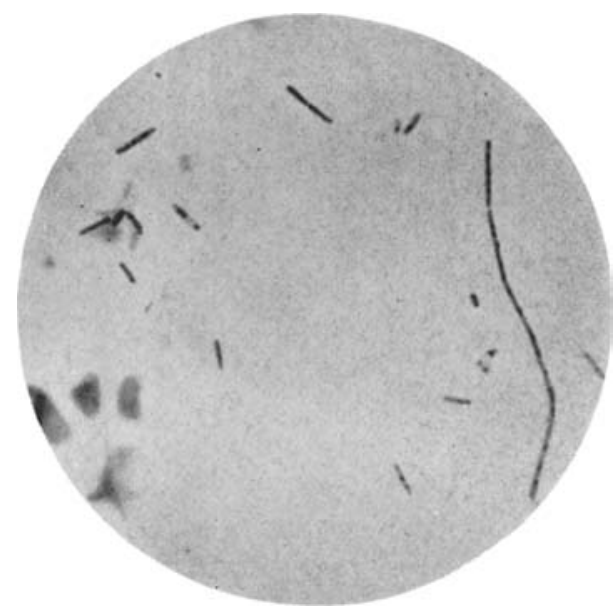

Fig. 6 (Case 3).-Smear of meibomian secretion.

A number of authors have found it in smears of various lesions, usually of the pharynx and respiratory tract. Leyden and Jaffé ${ }^{\text {found masses of }}$ unbranched threads and spores in the plugs of sputum in putrid bronchitis. Introduction of these plugs by tracheotomy into rabbits produced fatal bronchopneumonia in some cases; the urganisms were found in sections. Feeding the plugs produced bloody diarrhea in rabbits. These authors found similar threads in decubitus ulcers, gangrenous wounds, the feces of cholera patients and in a closed abscess of the tongue; in the latter they formed small, hard concretions. In mycoses of the mouth Leptothrix has been found by Michelson, ${ }^{7}$ Fraenkel,

2 Kolle u. Wass. Hdbch., 1903, 2, p. 832.

Zentralli, f. Bakteriol., 1904, 36, p. 369.

4 Handbuch der klin. Mik., 1887; Virchow's Arch.. 1884, 98, p. 441.

5 Bakteriologie der Mundhöhle, 1894.

- Dentsch. Arch. f. k1in. Med., 1867, 2, p. 488.

7 Berl. klin. Wehnschr., 1889, 9, p. 284.

s Quoted by Petruschky. ${ }^{2}$ 
Chiari," Stoos, ${ }^{1 "}$ Dubler, ${ }^{11}$ Hering, ${ }^{1 "}$ Councilman, Malloy and Pearce, ${ }^{13}$ Epstein, ${ }^{14}$ Wright, ${ }^{1.5}$ Newcomb ${ }^{16}$ and others.

Dubler's patient died of bronchopneumonia, and white flecks consisting of Leptothrix masses were found on the mucosa of the mouth, esophagus and larynx. Sections showed the organisms under the epithelium, in the glands and in the lymph nodes.

Hering's findings werc in the tonsillar crypts of 6 cases. He inoculated rabbits with the plugs subcutaneously, and produced small abscesses, from which however the organisms were not recovered. Newcomb found Leptothrix in two types of cases: first, in cases of folliculosis lacunaris, in which the organism was purely saprophytic, and second, in true mycoses caused, he says, by the Leptothrix.

Von Arx ${ }^{17}$ besides one case of tonsillitis, found the organism in two cases of phlegmon of the neck, one associated with carious teeth, but in all the other

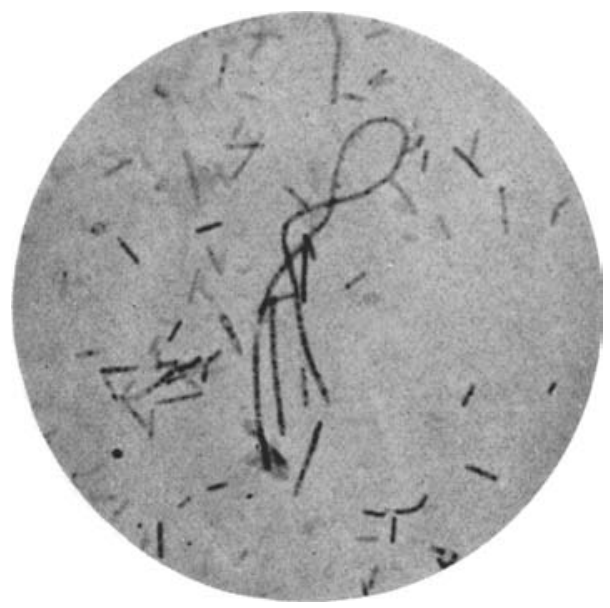

Fig. 7 (Case 3).--Smear of meibomian secretion showing spores.

cases mouth organisms were also present and only a few threads were grown in mixed culture. He mentions a similar case of Niehaus, with positive cultures. but it seems doubtful from his description that the organism recovered was a Leptothrix. Injection of the pus subcutaneously killed a guinea-pig, but a mixed culture was recovered. Vaginitis, in which Leptothrix was found, is reported by von Herff. ${ }^{18}$ Pearce ${ }^{19}$ found it in smears and sections from a case

- Rev. Mens. de Laryngol., Otol. \& Rhinol.. 1887, 7, p. 559.

10 Quoted by Petruschky.

1 Virchow's Arch., 1891, 136, p. 454.

1. Ztschr. f. klin. Med., 1883 7, p. 358.

13 Councilman, Mallory and Pearce: Quoted by Pearce. ${ }^{1:}$

14 Prag. med. Wchnschr., 1900, 15, p. 253.

1 1. Laryngoscope, 1898,4, p. 221.

16 Laryngoscope, 1898 4, p. 246.

1 i Correspbl. f. Schweizer Aertze, 1889, p. 161.

is Sammlung klin. Vorträge, $1895,137$.

1" Univ. of I'enn. Mcd. Bull., 1901, 14, p. 217. 
of necrosis of the larynx perforating into the esophagus and in the biliary ducts of a patient dying after an operation for gallstones. Animal inoculation was negative. Naunyn's ${ }^{20}$ finding of Leptothrix on the pia mater and vegetations in the heart of a patient with chorea is doubtful because the organs had been washed in tap water which contained similar organisms. Majocchi, ${ }^{21}$ in a series of concretions of the salivary ducts, found that some were caused by each of three organisms: Leptothrix, Streptothrix Foersteri, and Actinomyces. Leber ${ }^{22}$ repeatedly inoculated rabbits' corneas with fresh material from the tonsils containing Leptothrix, and observed progressive lesions of the cornea, sections of which showed Leptothrix elements. He appears not to have worked with pure cultures.

It is only necessary to mention briefly the discussion among dental pathologists centering around the work of Vincentini. ${ }^{23}$ This author ascribed a large number of our ills to infection by forms of Leptothrix, but the elaborate life cycle of the organism he described places it definitely outside the group of leptothrices that other observers have studied in culture and among those higher moulds that some botanists classify as Leptothrix.

In the ophthalmologic literature, a large number of concretions of the canaliculi purporting to be formed by Leptothrix have been reported. Most of these were studied in smears and secretions only, and it is the opinion of Axenfeld ${ }^{24}$ and others who have studied cultures that nearly all such concretions are due to a Streptothrix; Streptothrix focrsteri or Streptothrix actinomyces (the author has studied 5 such concretions, in 2 of which pure cultures were isolated, and all showed the branching threads of Streptothrix). Fifteen observers of these concretions called the organisms found Leptothrix, but since the branches of Streptothrix may be so small as hardly to be noticed in smears or sections, Axenfeld justly concludes that a diagnosis of the Leptothrix is not justifiable without cultures. Of this group, Cannas ${ }^{2 \pi}$ alone obtained Leptothrix in cultures; and this under somewhat doubtful circumstances. Thus, though some of these cases may have concerned Leptothrix, this cannot be said to have been proved except possibly in the case of Cannas. Verhoeff and Derby ${ }^{26}$ and Keiper ${ }^{27}$ found Leptothrix in sections of excised conjunctiva and of preauricular glands in Parinaud's conjunctivitis, but these observations are open to the same objection, no cultures being obtained and sections being, in some ways, even more unsatisfactory than smears for the study of threadlike organisms.

The same may be said of the other cases reported alove, in which no cultures were obtained. In a few cases, however, cultures of Leptothrix have been definitely successful. I was able to find only two reports of observers who have definitely isolated Leptothrix from lesions and three from normal tissues; also more doubtful cases.

Arustamow, ${ }^{28}$ in repeated smears and cultures from the urine of a tabetic, found threads 8-50 mikrons long and 0.5-6 mikrons thick. Pure cultures were obtained with great difficulty, growing slightly and only anaerobically better

so Rev. in Baumgarten's Jahresber., 1888, 4, p. 296.

21 Arch. per le scienze med., 1892, 16, No. 15. (Quoted by Cannas. ${ }^{25}$ )

w Centralbl. f. d. med. Wiss., 1873; Berl. klin. Wehnschr., 1882, p. 161.

23 Dental Cosmos, 1900, 1901, 1903.

24 Bacteriology of the Kye, 1908.

25 Ann. di. Ott., 31, p. 606.

20 Arch. f. Augenh., 1913, 75, p. 207.

27 Ophth. Rec., 1914, 28, p. 109

23 Centralbl. f. Bakteriol., 1890, 6, p. 349 . 
in acid mediums. The organism was nonmotile and showed refractile deeply staining bodies in old cultures, which the author thought were probably spores though they were not viable after 3 months. The organism did not grow at room temperature, and did not liquefy gelatin.

From the tonsillar crypts of two cases of tonsillitis he isolated an organism morphologically similar to the first, but growing aerobically very freely, forming a folded gray coat on agar. It formed a heavy pellicle on broth, was nonmotile, grew at room temperature, and liquefied gelatin. It showed also septums in the threads, which the first organism did not show. It showed sporelike bodies, and was viable after three months. Both organisms were only one-third as thick as Vignal's organism and those of Klebs and Rasmussen. Arustamow says that Affanassieff obtained a culture of a similar organism, but no reference to it could be found.

The author reports no animal experiments.

Cozzolino ${ }^{29}$ obtained clear-cut and complete results in a case of periauricular swelling in a young girl, who died from a large retropharyngeal abscess and symptoms of basilar meningitis 6 months after her first visit. There was boardlike swelling of the neck, clinically like actinomycosis; but smears and cultures from the periauricular swelling, the retropharyngeal abscess, and the lungs, kidneys, spleen, brain and medulla all showed the same organism, which must be identified as a Leptothrix. Smears showed long coils of gram-positive unbranched threads and some bacilli. Granules found in the pus were composed of a central mass of threads and an outer fringe of threads with clubbed ends.

Thirty pure cultures were obtained from the different organs. On the various mediums the organism behaved somewhat like the organism from the author's case 1 , growing slowly aerobically at room temperature, well at 37 dęgrees and at a temperature as high as $60 \mathrm{C}$. It liquefied gelatin and serum, precipitated the casein in milk and reduced lacmus. The spokelike lodies found both free and in threads stained only faintly with Moeller's spore stain, but resisted heating to $100 \mathrm{C}$. for 15 minutes; hence they were evidently spores. No branches were seen in cultures. The organism formed reddish pigment, however, on serum and egg-white and a pellicle on broth; its growth became dry and folded, differing in these particulars from the organism of case 1 . The young bacilli in Cozzolino's case also showed rapid independent motility. Its pathogenicity resembled that of this organism, being marked for guinea-pigs and negative for rabbits and white mice. A guinea-pig died 19 hours after subcutaneous injection. The organism was also pathogenic for house mice. Cozzolino called his organism B. filiformis, but it is evidently a form of Leptothrix.

Vignal, ${ }^{3}$ in a series of plate cultures from the tartar of normal teeth, isolated a slow-growing aerobic organism, forming unbranched threads 1.6 to 30 mikrons in length. Cultures resembled those from case 1 , but no spores were mentioned. Tests for pathogenicity were not described."

Bordoni-Uffreduzzi, ${ }^{3:}$ from the skin between the toes and in the groin of normal persons and those with intertrigo, isolated a Bacillus epidermis which they say is identical with Bizzozero's Leptothrix epidermis. It grew at room temperature on the surface of agar, serum and potato, forming a wrinkled gray

w9 7tschr. f. Hyg. 1900. 33, p. 36

* Arch. de Phys., 1886, 8, p. 325.

31 Though Bizzozero (4) describes completely the morphology of Leptothrix epidermidis as he found it on the normal skin and the skin in intertrigo, I could find no work of his in which he described cultures.

Fort. d. Med., 1886. 4, p. 151. 
coat on agar. It gave little growth on gelatin and evidently did not liquefy it. It formed spores, becoming free as the threads broke up. The threads were 0.3 mikron in diameter (much thinner than those of Vignal and the author), and were separate, breaking up into shorter rods.

Inoculations into guinea-pigs, rabbits and the author's own skin were negative.

Lehmann and Neumann ${ }^{23}$ evidently grew a Leptothrix from the skin. Their organism formed unbranched septate threads, grew freely on the usual mediums aerobically, liquefied gelatin and was gram-positive. It differed from the author's organism in forming brownish-yellow pigment, a pellicle on broth and milk, folded coat on agar, in that the young rods showed active motility and in the absence of spores.

Reports with positive culture in which the diagnosis was more doubtful are the following: Flexner ${ }^{34}$ isolated an extremely pathogenic organism from the uterus, serous cavities and viscera of a rabbit dying 5 days after abortion. A dense network of threads 1.4 to 154 mikrons long was found to cover all the serous surfaces. The organism showed no growth on ordinary mediums and was only grown on sterile rabbit tissue. Inoculations from the tissues and from these tissue-cultures caused fatal peritonitis, meningitis, abortion and septicemia in rabbits and guinea-pigs, but were negative in mice, pigeons and one dog. The organism is described as gram-negative, though with deeper staining dots, globules and cylinders within the threads. It often showed a grouping in sheafs, radiating from an apex or in rosettes, in which it resembles cladothrix. It formed no spores, as it was killed by drying and heating to $55 \mathrm{C}$. It showed no branches. Flexner called it Bacillus (Leptothrix?) pyogenes filiformis. Follet and Sacquepee ${ }^{2}$ isolated what they called Leptothrix from the pustules of a case of herpes zoster of the abdomen. The organisms grew on ordinary mediums and formed long threads. The threads, however, showed frequent false branding. The shorter forms were actively motile. No spores were described. The organism produced nonfatal peritonitis in guinea-pigs." The organism isolated by von Dobrzynieckj ${ }^{36}$ from a root-filling removed from a tooth is called hy him Leptothrix placoides alba, and was grown in pure culture. His pictures of it, however, show what appears to be true branching. Rosenbach ${ }^{37}$ isolated from the lesions of a dermatitis common among fishmongers, a threadlike organism which showed false branching only, and which he thinks is a species of Cladothrix. It formed clubshaped terminal bodies thought to be spores. It grew on gelatin, and cultures produced similar lesions on the author's own arm. Schmorl, ${ }^{38}$ from an infectious disease of rabbits starting in the lips and producing local necrosis and later peritonitis, obtained a thread organism that grew only on anaerobic blood serum. Cultures produced similar lesions in rabbits, and were pathogenic for white mice, but not for other animals. No branches were described, and the organism is classed as a Leptothrix or a Cladothrix (the original reference was not in the Surgeon-General's Library). Jacobson ${ }^{3 \theta}$ grew a threadlike organism without branches from the tonsillar crypts, but describes no single colonies on plates, and the reviewer doubts that a pure culture was obtained. Arustamow considers his cultures an

33 Bakteriol. Diag. 1896, p. 395.

34 Jour. Exper. Med., 1896, 1, p. 211.

* Bull. d. hóp. de Par., 1902, 7, p. 568.

so Centralbl. f. Bakteriol., 1897, 21, p. 225.

* Arch. f. klin. Chir., 1887, 36, p. 346

38 Ztscht. f. Thiermed., 1891, p. 375. Rev. in Baumgarten's Jahresbericht, 1893, 9. p. 7.

* Rev. in Baumgarten's Jahresbericht, 1888, 4, p. 283. 
organism from poorly sterilized potato. Cannas, ${ }^{2.3}$ as mentioned above, grew from a lacrimal concretion an organism forming unbranched threads. It grew easily on ordinary mediums when once isolated, and was evidently a Leptothrix. However, since only one colony of it grew from the original material, other organisms being present, Axenfeld doubts whether it was the responsible organism.

\section{SL'M MARY}

It seems fairly certain that there are several distinct organisms within the group of Leptothrix. Miller's distinction of four species of Leptothrix bucealis on the basis of morphology in smears and the iodin reaction is, however, unsatisfactory. There seems to be no biologic distinction between Leptothrix epidermidis and Leptothrix buccalis, organisms from both the skin and the mouth probably falling in one of several species.

The only definite evidence of such grouping must be obtained from the few strains grown in pure culture. Properties of such organisms, about which sufficient data were given to justify their being called leptothrices, are summarized in table 1.

This shows differences in properties, of more or less importance in all the strains for which the data are at all complete. A few common properties may be noted. All were aerobes, except Arustamow's strain 1. All were gram-positive (when this was mentioned) except Flexner's organism. All were nonmotile, except those of Cozzolino and Lehmann and Neumann. Those that grew freely at room temperature, all liquefied gelatin except the strain of Bordoni-Uffreduzzi and the author's strain 2. None formed pigment except those of Cozzolino and Lehmann and Neumann, which agree more nearly than any other two, both being motile and forming pigment. The author's strain 1 was much like these two except in the last two respects and in its not forming pellicle on broth. Of the author's two strains, 1 grew freely even at room temperature, formed long threads with many free spores and no clubbed ends, and was definitely pathogenic; while 2 grew delicately, formed shorter threads with fewer spores, showed threads with clubbed ends, and was nonpathogenic for animals. Serologically 1 showed no relation to 2. Arustamow's strain 1 and Flexner's organism are each quite different from all the. others.

Out of such a confusion of small differences, it would be useless to attempt a definite classification. The property of spore-bearing. however, seems to the author to be less subject to special conditions than most of the properties enumerated, and in this case more than a matter of one or two exceptions. The author's two strains, Cozzolino's 


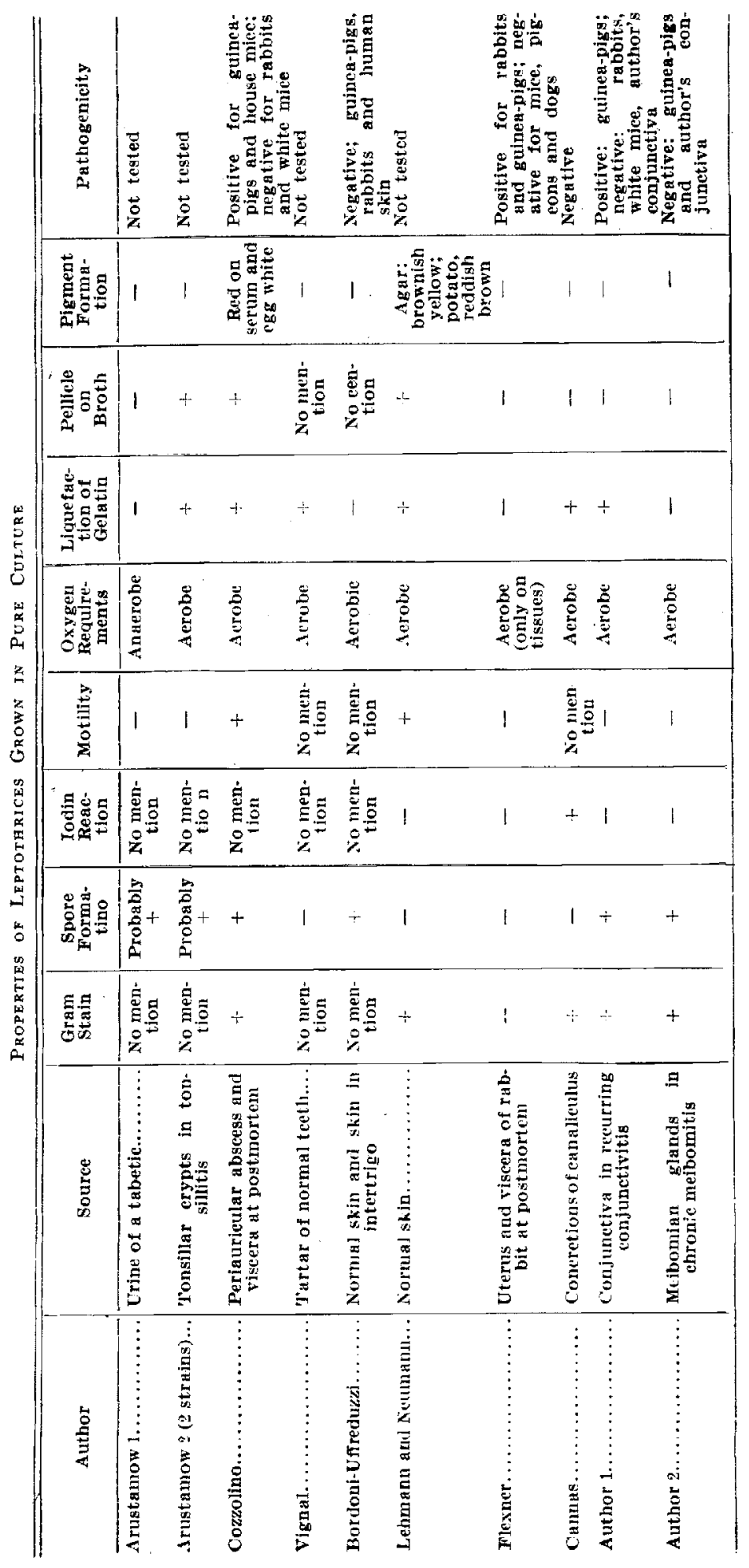


strain and the skin strain of Bordoni-Uffreduzzi, showed definite spore-formation, and Arustamow's strains with the author's case 3 showed what were probably spores. Those of Flexner, Lehmann and Neumann, Vignal and Cannas, showed none. It might be worth while to place the first mentioned organisms in a tentative group of Leptothrix sporogenes, calling the others Leptothrix simplex. As more pure cultures are reported, these groups will probably be found to contain several distinct species. It may be found, however, that all forms may produce spores under certain conditions.

There can be no doubt, especially in view of Cozzolino's results, which are borne out by the author's and probably also by those of Flexner, that true leptothrices can be distinctly pathogenic for man and animals. It seems likely that many of the reports of Leptothrix in smears alone, as a pathogenic organism, especially in the upper respiratory tract, really did concern Leptothrix. The finding of Leptothrix in the ocular apparatus makes it more probable that some of the cases of lacrimal concretions said to have been caused by Leptothrix, really were caused by that organism and not by Streptothrix, though Streptothrix is undoubtedly much the commoner agent.

Whether there are fast pathogenic strains of Leptothrix or whether the ordinary Leptothrix of the mouth and skin becomes pathogenic under certain conditions cannot be stated. The most likely source of Leptothrix in the eye would seem to be from the mouth by way of a finger, though it may prove to migrate occasionally from the skin of the lids into the meibomian or other glands and thence to the conjunctival sac.

\section{CONCLUSIONS}

A strain of Leptothrix was found as the only organism in smears and cultures from the conjunctival sac in a case of recurrent conjunctivitis. It was pathogenic for guinea-pigs and showed definite sporeformation.

A Leptothrix was isolated from a case of chronic meibomitis. It showed definite spore-formation, but was nonpathogenic for guineapigs, serologically distinct from the first strain, and presented cultural differences from it.

What is probably a Leptothrix was found in smears from a second case of chronic meibomitis. It apparently showed true spores.

The group of leptothrices includes at least two, and probably more, distinct species. 